\title{
A DECISION RECONSTRUCTION SUPPORT MODEL
}

\author{
Francisco Antunes \\ Management and Economics Department, Beira Interior University and INESCC, R. Antero de Quental, 199 \\ 3000-033 Coimbra, Portugal \\ francisco.antunes@ubi.pt \\ João Paulo Costa \\ Faculty of Economics, Coimbra University and INESCC, R. Antero de Quental, 199 \\ 3000-033 Coimbra, Portugal \\ jpaulo@fe.uc.pt
}

\begin{abstract}
The importance of understanding the reasons for past decisions is not a new subject. However, there seems to be a gap when it comes to verifying the efficiency of tools for understanding past decisions. In this paper we show that the ability to perform decision reconstruction using a Group Support System (GSS) can provide a flexible solution to the problem, but only if the information model underlying it is able to provide bidirectional support to the phases of a decision-making process. For this, we present a general information model to support the decision-making process, as well as the decision reconstruction process. We tested these ideas by setting up a case study where we used a GSS, based on our model, to analyze a simulated public contracting process. We present a discussion of the results.
\end{abstract}

Keywords: Decision Reconstruction, GSS, Information Model.

\section{Introduction}

Distributed decision-making follows naturally from the virtualization of organizations and the geographical dispersion of the decision agents. ${ }^{1}$ By virtualization, we mean the process of incorporating information and communication technologies and their exploitation for strategic goals. ${ }^{2-4}$ Group support systems (GSSs), in particular, facilitate the seizure of knowledge, ${ }^{5}$ namely by capturing and retaining encoded knowledge ${ }^{6}$ and enhancing collaboration. ${ }^{7-8}$ GSSs supply a collaborative learning context where people can interact, create and obtain knowledge, acquired and shared by groups, ${ }^{9}$ while providing structured opportunities to engage in deliberative exploration of ideas, evidence and argument. ${ }^{10}$

The repositories of a GSS, drawn from electronic group meetings, keep and offer a group memory to group meeting participants who need to access historical information or knowledge for recommendations. Combining a GSS with the collective memory is also likely to provide additional information processing support, ${ }^{11}$ especially when information and knowledge are not easily accessible in large organizations.

In this context, GSSs are a natural solution for the demands of distributed organizations when it comes to support decision processes, as they cover a wide range of services, or features (described in detail, for instance, Ref. 12 and Ref. 13), which must be chosen according to the specific situation and group to support. In order for users to 
obtain the newest information, GSSs also provide the ability to manage successive versions of the information and to maintain a record of the people involved, while enabling the arrangement and classification of information, which eases its retrieval. ${ }^{14}$

We will address GSSs throughout the paper using a broad concept (as set out in Ref. 15), in which such systems are seen not only as a communication support, but also as decision-enabling technology, supporting the different stages of a decision process. These stages are: 1) the identification and listing of all the alternatives - intelligence phase; 2) the determination of all the consequences resulting from each of the listed alternatives design phase; and 3) the comparison of the accuracy and efficiency of each of these sets of consequences - choice phase. ${ }^{16}$

This paper presents a model to support decision-making processes along with the reconstruction of past decision processes, in which establishing relationships between group discourse elements, with relevant meta-data, provides the necessary information to perform decision reconstruction and to visually structure and represent a GSS-based discussion. In order to test our ideas we used a GSS, based on the defined model, to analyze a public contracting process, from which we point out some interesting results.

In the next section, we frame our research problem according to the literature. To overcome the detected problems we define the constructs for a decision reconstruction in the third section, as well as the details of an information model that supports it. In the fourth section we describe the working environments of a system based on the decision reconstruction model and their connection to the components of the model. In the fifth section, we present a case study, describing its methodological bases and settings, and discuss the obtained results and limitations. We dedicate the last section to final remarks and future research considerations.

\section{Decision Reconstruction}

The importance of understanding the reasons for past decisions, whether for knowledge or auditing purposes, is not a new issue (this appraisal can be found, for instance, in Refs. 13, 17-19). A system with decision reconstruction capabilities seems particularly useful in public contracting, as it would support the decision agents in charge of public sector activities in reaching decisions. It would also help applicants if they could reconstruct such decisions, as it would enable them to understand the processes involved and even to detect possible manipulations in real time. We believe that this situation can enhance transparency (as stated in Refs. 20-21), and will empower GSSs as tools for public consultation and the external scrutiny of decisions, as well as effective means to achieve the aims of legislative initiatives such as the European Transparency Initiative $e^{22}$ or the American Sarbanes-Oxley Act. Both projects intend to pressure organizations to register every aspect of their decision-making: the parties and their organizational role, documents, procedural steps and even tasks that may not have started yet, easing future audits. $^{17-18,23}$

We define decision reconstruction as the process that allows an individual or group of individuals (the decision reviewers), whether internal or external to the organization, to understand how a GSS supported group has reached a previous decision. We also 
comprehend the concept of decision reconstruction in lato sensu, meaning that the utility of the construct fits the needs of the organization's internal and external users, as well as the ones of the usually independent examiners, normally known as auditors. We find the decision reconstruction concept preferable to a decision-auditing concept, as audits (internal or external) carry a certain connotation of mistrust or even an intention to find whether a past decision was indeed the best solution. Although this line of reasoning seems valid (and even necessary), our research only focuses, at least for now, on the use of a GSS solution as an technical element for organizational memory (as defined, for instance, in Refs. 6, 24-27) and its ability to effectively describe past discussions, as well as the steps involved in them.

Research on decision reconstruction seems to have been directed towards building and using visualization tools rather than verifying the efficiency of such tools in understanding past decisions. Literature on expert system shows an interest in explaining (rebuilding) decisions. However, the specificity in developing explanation subsystems and, especially, the normative character of such software, make them unsuitable for the needs of dynamic groups that require collaborative work.

As stated in the introduction, GSSs are a natural solution to handle this kind of work. Nevertheless, as GSSs are built upon the idea of sequential support (see Ref. 28, for a thorough discussion on the advantages of using technology that provides clear and simple instruction on good problem solving practices instead of a complex array of tools, at least on the case of ill-structured problems) for the decision-making stages, ${ }^{16}$ it is not always easy to understand the earlier stages of a discussion. This is particularly evident at the end of discussions when classes, which were created to encompass the discussion elements and some of the details, are "flattened". For instance, in a GSS voting environment, it is usual to expect changes in initial votes, as part of the group process. ${ }^{29}$ Even if people are allowed to review their votes (for instance, after discussing the results), when the decision is made and results are disclosed, the final report is poor when it comes to show discussion progress, changes of opinions (and by who, if possible), convincing arguments, etc., which were involved from the start of the discussion to its end. In this case, a new group iteration (which could be the point when a vote changed) substitutes the earlier one, discarding the previous discussion scenario. However, reports usually only embed the latest result, especially when reporting is an automatic feature.

Our study shows that performing decision reconstruction, using a GSS solution, can provide a more flexible solution to the problem. However, this can only happen if the information model underlying it is able to support and structure the collaborative discourse (as defined by), thus supporting both the decision process from stage 1 to stage 3 and the reverse process (from stage 3 to stage 1 ).

When supporting a decision-making process, GSSs play an important role in registering and codifying group's contributions, thus enriching the organizational memory. By fostering the decision reconstruction ability of GSSs, we promote their capability for information retrieval, thus contributing to ease and deepen the comprehension of past decisions, while fostering knowledge acquisition. In addition, expanding GSSs capabilities from the perspective of knowledge management can significantly improve the performance and satisfaction of group meeting participants. ${ }^{30}$ 
Although GSSs might foster relationships between information, linking discussions is not an always-present feature, as group discussions are usually independent. The situation means that though group participants can retrieve information from other discussions and "copy/paste" the information between discussions, the software does not recognize that there are intertwined elements among discussions. To perceive such connections, organizations often need to resort to other systems (for instance, search engines using artificial intelligence techniques, based on natural language recognition, or document similarity measures ${ }^{31-32}$ ) to generate categories in order to integrate information.

Decision makers must understand how the past affects their present decisions. In this matter, we stand that expanding the ability for explicitly interconnecting GSSs discussions facilitates the search and extraction of relevant information from the organizational memory and mitigates the need for more elaborate (and usually more expensive) software to retrieve information. It also enhances the possibilities for an accurate decision reconstruction, since all decision elements (whether or not discussed within a single discussion) would be available, thus fostering relationships between information and facilitating the use of knowledge in mutually dependent contexts. ${ }^{33}$

\section{A model for decision reconstruction in GSS}

Beyond the ability to structure and support group interaction in different modes, we find that GSSs require additional properties when the goal is decision reconstruction. Part of the problem is that GSS solutions need to cover a multiplicity of approaches to support different ways of building a collaborative discourse (according to Ref. 19). These ways range from a simple question-reply pattern to more elaborate argumentation models supported by argumentation theory (as seen, for instance in Refs. 34-37). A general GSS information model for decision reconstruction needs to be able to register (document) the in-between steps of the convergence/consensus-building provided by the interconnection of the argumentation elements presented by the group, during the discussion. This type of behavior resembles the capabilities of entity-based versioning systems, which can create versions of packages, classes, and even individual methods of a complete system over its entire lifespan. ${ }^{38}$ The fine-grained ability to version argumentation elements allows its indepth registration and to evidence their evolution over time. 


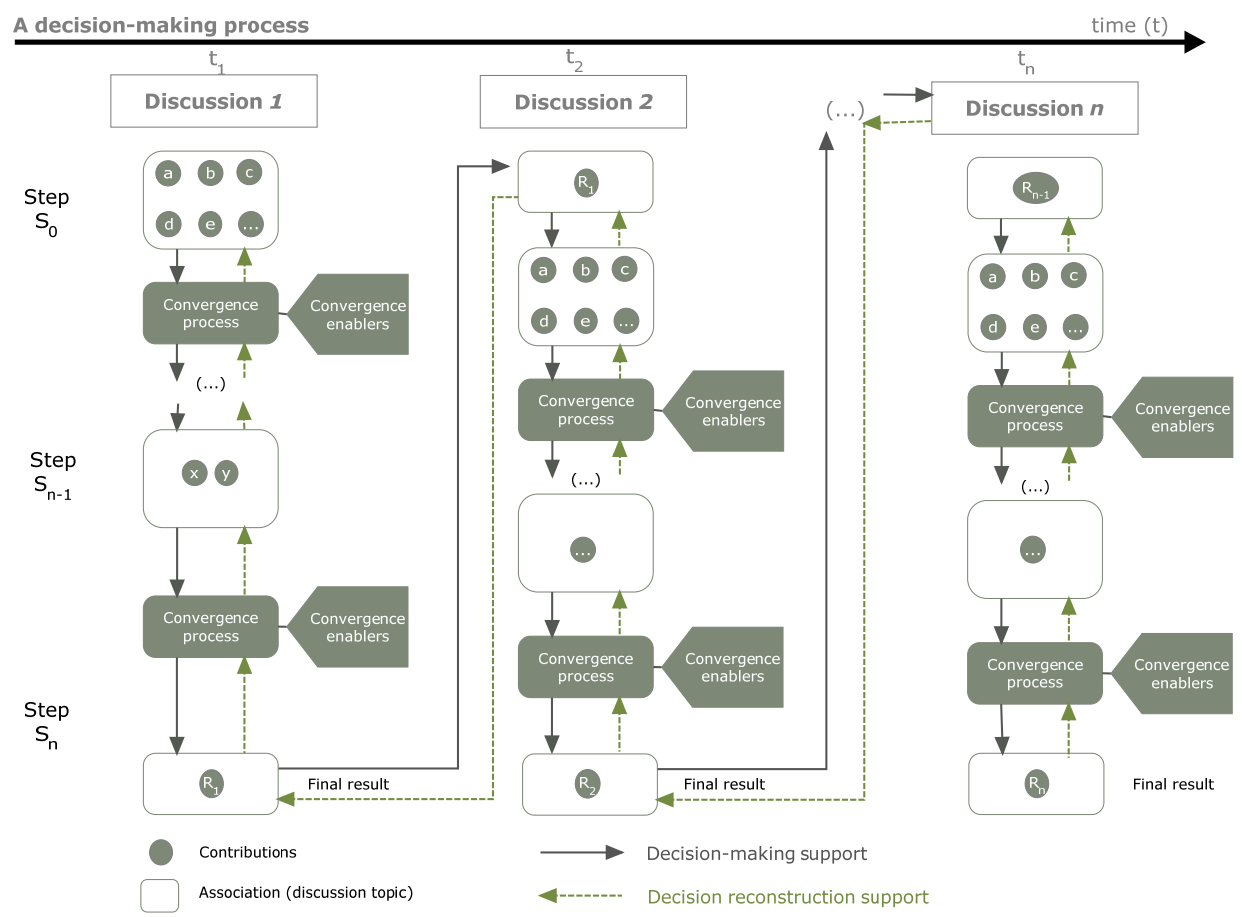

Fig. 1. Information behavior

Fig. 1 represents the described situation. In this case, the outcome of discussion $1\left(R_{1}\right)$ becomes the starting point for discussion 2, explicitly maintaining the connection to the previous discussion and therefore making possible to reconstruct the decision-making in discussion 2, as the first discussion influenced the second. The association to elements of earlier discussions (whether the final decision or some of the in-between steps) can be linked into a discussion in any stage and not just at its beginning (Fig. 1 is represented this way merely to preserve its readability), granting the possibility for deepening the decision reconstruction process whenever needed. This process allows adjusting the level of detail and time-span of the decision reconstruction analysis.

Another challenge in organizational memory regards the validity of the embedded information. When information expires (whether based on administrator's decisions or determined by existing laws), a cleaning process can occur. We stand, however, that the deletion of such information might constitute an important barrier to decision reconstruction, even when earlier information is "flattened" to some condensed form. To this matter, no records could mean no memory and, consequently, the inability to retrieve past decisions.

As we intend to register all the steps in decision-making to foster decision reconstruction, instead of deleting information, contributions could be marked as "active" or "inactive" in order to be considered in the group analysis (meaning that an inactive contribution represents a "deletion" but without actual information loss). Although this 
option is memory consuming, it does not seem problematic, as persistence means tend to lower in cost and increase in capacity.

We stand that it is possible to embed the previous characteristics into an information model to support both decision-making and decision reconstruction, by incorporating three different, though implicitly intertwined, types of support needs, as summarized in

Table 1.

Table 1: Support needs

\begin{tabular}{|c|c|}
\hline Decision process & Reconstruction process \\
\hline \multicolumn{2}{|c|}{ Argumentation } \\
\hline $\begin{array}{l}\text { - Cover a multiplicity of argumentation models. } \\
\text { - Express the relationships among the argumentation } \\
\text { elements. }\end{array}$ & $\begin{array}{l}\text { - Maintain and evidence the linking scheme of } \\
\text { the used argumentation model. }\end{array}$ \\
\hline \multicolumn{2}{|c|}{ Structure } \\
\hline $\begin{array}{l}\text { - Create meaningful categories. } \\
\text { - Register information evolution in time. } \\
\text { - Link information element between discussions. }\end{array}$ & $\begin{array}{l}\text { - Review of the in-between steps of a decision } \\
\text { process. } \\
\text { - Turn information elements into an "inactive" } \\
\text { state, instead of their deletion. }\end{array}$ \\
\hline \multicolumn{2}{|c|}{ Decision-making } \\
\hline $\begin{array}{l}\text { - Use computer-guided decision-making techniques } \\
\text { (such as statistical analysis, mathematical algorithms, } \\
\text { multi-attribute utility theory, multi-objective linear } \\
\text { programming, restructurable modelling, game theory, } \\
\text { non-linear optimization }\left({ }^{39}\right) \text {, ThinkLets }\left({ }^{40}\right) \text {, etc.). } \\
\text { - Use manual convergence methods (like voting, manual } \\
\text { selection, collaborative convergence processes }\left({ }^{4}\right) \text {, } \\
\text { etc.). }\end{array}$ & $\begin{array}{l}\text { - Access the details of the performed } \\
\text { convergence processes. }\end{array}$ \\
\hline
\end{tabular}

Fig. 2 represents our model and its abstract components. We describe the components of the model and its relationships in the next subsections. 


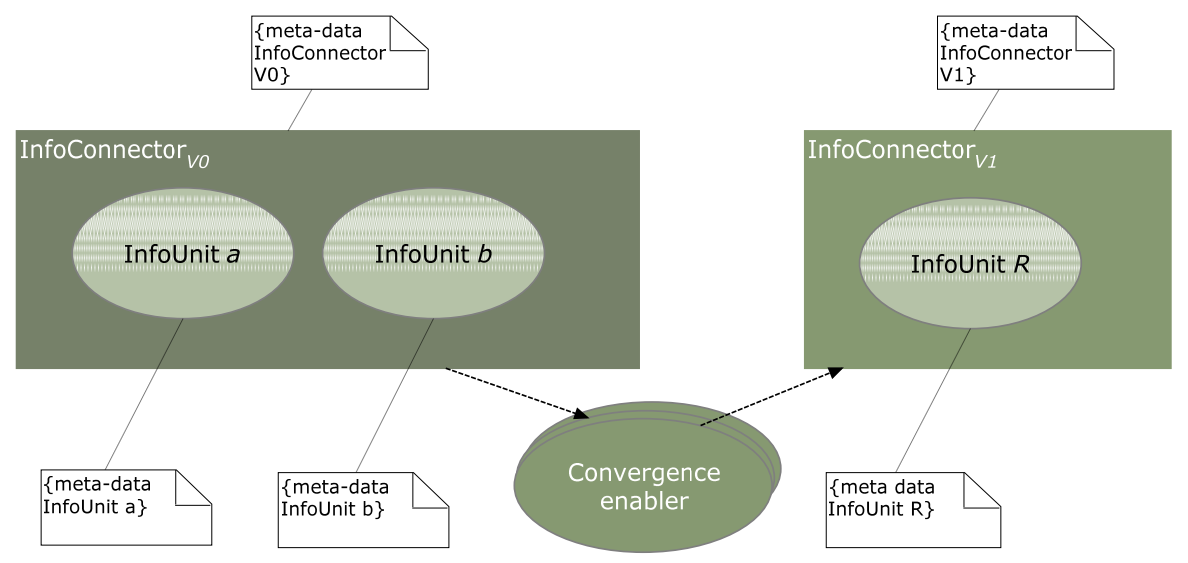

Fig. 2. A general information model for GSS decision reconstruction

\subsection{InfoUnits}

These elements receive and store a group's contributions. They require additional characterization (performed trough the Meta-data element) to define their argumentation role within the GSS (e.g. as claims, issues, rebuttals, backings, statements, propositions, etc.). Although InfoUnits can receive any type of contribution, it is possible to restraining their supported data types, which forces the group to comply with predefined data formats (e.g. numerical or textual), in order to ease the integration with the Convergence Enabler element, as described ahead.

InfoUnits are independent elements and connecting them is necessary to capture their context or relationships (by means of InfoConnectors). Users are also modeled as InfoUnits.

\subsection{InfoConnectors}

InfoConnectors capture the relationships among InfoUnits. The type of connection relies on the Meta-data element associated to InfoConnectors (as these are mere void links among InfoUnits). There are different types of expressed connections:

- argumentation model relationships (e.g. support, response to, evidence for, etc.);

- structuring support (as one of the most common features in GSS is their ability to separate contributions into meaningful categories or information containers, namely, discussions, topics, categories, information "buckets", documents, etc.);

- and time-span association (sequence, dependence, versioning, merging, etc.).

The earlier relationships guarantee that a combination of InfoUnits, InfoConnectors and their associated Meta-data can support every argumentation model, while preserving the flexibility of GSS to organize information.

Depending on the discussion, decision-making support might benefit from the use of formatted contributions or from predefined data-types used when inserting data, especially when quantitative data is under analysis (e.g., percentage numbers, weights, etc.). Therefore, InfoConnectors can establish data validation rules over InfoUnits, in 
order to ease or automatically support later convergence processes, using Convergence Enablers.

\subsection{Meta-data}

The generation of InfoUnits and InfoConnectors implies the creation of an associated Meta-data element, which contains a dynamic list of properties. These properties range from automatic indexing information (such as identification, authoring, time stamping, etc.), to additional properties that can be set to register personal annotations and measures for defining the affective value of information objects. ${ }^{42}$ That sort of information provides the needed elements to establish categorizations that deepen contextual information and help users to understand, use and extract information, while reducing possible information ambiguity. ${ }^{43}$

To bridge the gap between GSSs and argumentation theory, Meta-data can also register argumentation model properties, referring to both InfoUnits and InfoConnector, as already mentioned. As different discussions (or discussion segments/phases) may require distinct argumentation structures, Meta-data offer the support for different argumentation models. This possibility allows a future reviewer to observe decisions using the underlying logic of different argumentation models, enhancing the support for a richer and accurate decision reconstruction.

\subsection{Convergence Enablers}

These elements support groups in achieving decisions when divergent contributions exist. Convergence Enablers implement decision-making techniques, and provide the versioning capability over the argumentation elements. Achieving the final decision, however, might require more than one convergence process (also meaning additional versions of the argumentation elements) and more than just one convergence method (whether manual or computer-guided). By maintaining a record of the convergence process, as well as the used methods, Convergence Enablers contribute to ease the decision reconstruction processes by saving and linking the in-between steps of the decision process.

\section{Implementing the model}

The development of our GSS, at this stage, is meant to demonstrate the feasibility of the model, as stated in design research, which frames this study (as further discussed in section 5.1). This system requires that users perform an initial registration process, for identification purposes within discussions. After such procedure, the system grants access to three different and sequential working environments: a structuring editor (for inserting and structuring group's contributions); a visual map tool (that visually represents the discussion elements), and a document production environment (in which a more "traditional" document can be created from the discussion elements). To further explain the previously described information model, we illustrate, in the following sub-sections, the GSS tools and functionalities that are used in both decision and reconstruction processes. To ease the description and its association to the described information model, 
we will use the following notation: $I U_{n}$ (InfoUnit); $I C_{n}$ (InfoConnector); $I U_{n}-M_{D}$ (InfoUnit and its Meta-data); I $C_{n}-M_{D}$ (InfoConnector and its Meta-data); $C_{E n}$ (Convergence Enabler); and $M_{D}$ (Meta-data).

\subsection{Structuring support}

To support discussions, the system uses a common metaphor in GSSs, where discussions (structuring $I C_{n}-M_{D} s$ ) encompass topics (also structuring $I C_{n}-M_{D} s$ ), which can aggregate other topics (sub-topics) and/or group's contributions or posts $\left(I U_{n}-M_{D} S\right)$. These elements are presented using a common threaded structure, as in internet forums. Once they are created or posted to the system, users are not allowed to delete information elements but only to mark them as active or inactive (by means of their $M_{D}$ ).

As the discussion progresses, group's contributions are posted into topics (using the messenger tool), as represented in Fig. 3. The argumentation sequence and properties of the contributions are supported and recorded using argumentation relationships $I C_{n} s-M_{D}$ that connect the different posts. Not only these same elements allow tracing back the posts in the reconstruction process, but also enable their visual representation, using the visual map tool (described in section 4.2).

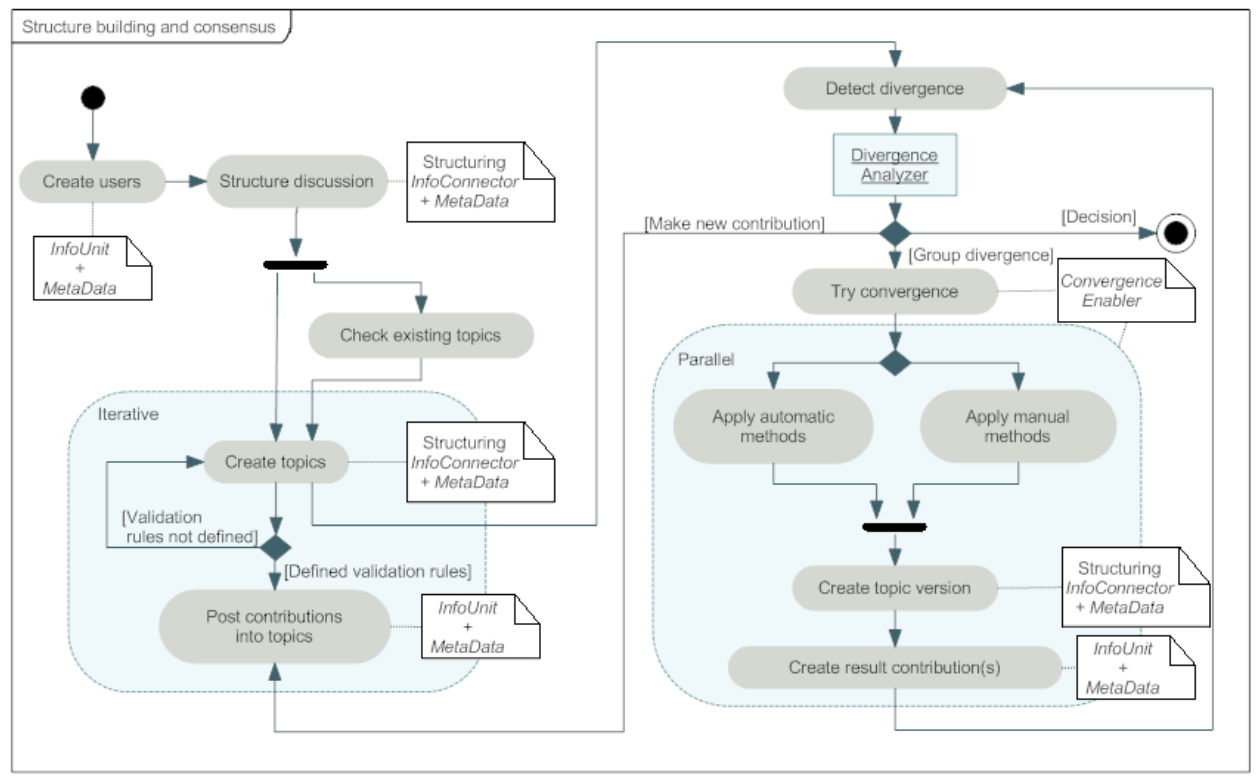

Figure 3: Structure building (activity diagram)

The $M_{D}$ associated to a specific topic define the type of accepted $I U_{n}$ and, consequently, determine the properties of their $M_{D}$ (e.g. a topic where a numeric value is under discussion might restrain the group's contributions solely to numbers and even apply validation rules, such as number intervals or sets of values). Unless it is the case of a previously defined type of topic, users are responsible for inserting the validation rules of a topic, before actually making any post to it. 
Discussions include regular users and a mediator (a role defined using its associated $I U_{n^{-}}$ $M_{D}$ ), whose tasks are initially assured by the creator of a discussion. Later on, the mediation can be transferred to any other user who belongs to the list of participants (it is possible to review the sequence of distinct mediators, by reviewing the associated $I U_{n^{-}}$ $M_{D}$ ). The mediator is responsible for coordinating the discussion, as well as dealing with situations that require human intervention, regarding convergence methods and even to make decisions when consensus is not possible.

To aid the consensus-building process, the system provides a tool for analyzing the existence of group divergence, which implements convergence methods (whose process characteristics are registered in distinct $C_{E n}$ ). The interactions of the consensus-building process are organized and represented as versions or steps (using time-span $I C_{n}-M_{D} S$ ) of the different discussion topics.

When the resolution process ends, the system generates a new version of the analyzed $I C_{n}-M_{D}$ with the corresponding convergent $I U_{n}$ or $I U_{n} s$.

Every $M_{D}$ associated to both $I C_{n}$ and $I U_{n}$, can be inspected using the properties viewer. By using this tool users can obtain the necessary information of the discussion elements, as versioning, convergence/divergence status, convergence methods that were used and divergent information criteria, etc., whether during the decision process or when performing the reconstruction process. Fig. 4 shows a snapshot of the structuring environment.

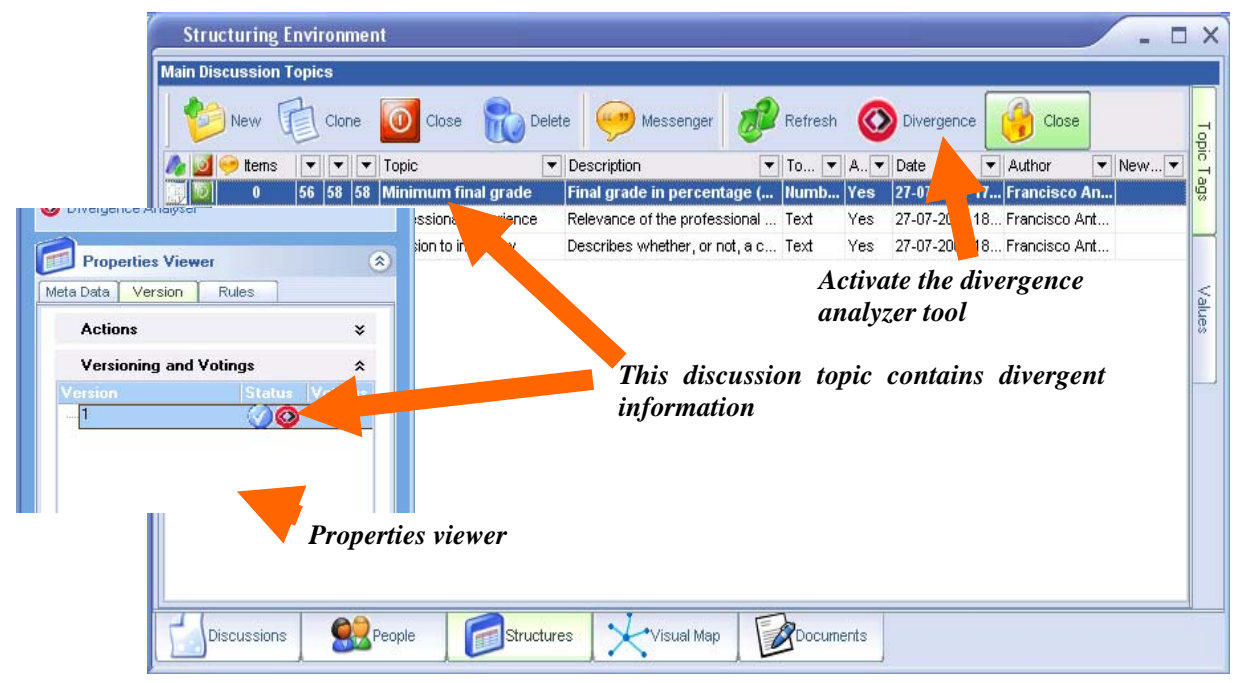

Figure 4: Structuring environment snapshot

\subsection{Activity tracking support}

Besides the threaded structure of the structuring environment, the visual map tool uses the $M_{D}$ of the discussion elements to organize them into a set of networked components, thus providing an environment for people to explore, discover, analyze and tap into information. ${ }^{44}$ Users can change its default representation, according users' preferences. 
Nevertheless, these changes only affect the visual arrangement of the elements and not the associated $I U_{n}, I C_{n}, C_{E n}$ and $M_{D}$.

The visual map tool organizes information so that it makes sense to the user, reduces working memory load and provides informative feedback and functionalities for both novice and expert users, thus constituting a highly efficient way for people to directly perceive data and discover knowledge and insights from it, as intended in decision reconstruction. The tool makes use of icons, color highlighting, linking, panning and zooming, since these techniques support dynamic and interactive use. ${ }^{45}$ Concepts such as knowledge mapping, hyperlinks, topic and usage maps (according to Refs. 46-48), as well as visual navigation, were also considered when developing the interface of the visual map tool. . $^{4-48}$

Switching between the structuring environment and the visual map is the basis for users who are trying to understand past occurrences or decisions during the decision process or within the context of a later decision reconstruction process (as represented in Fig. 5).

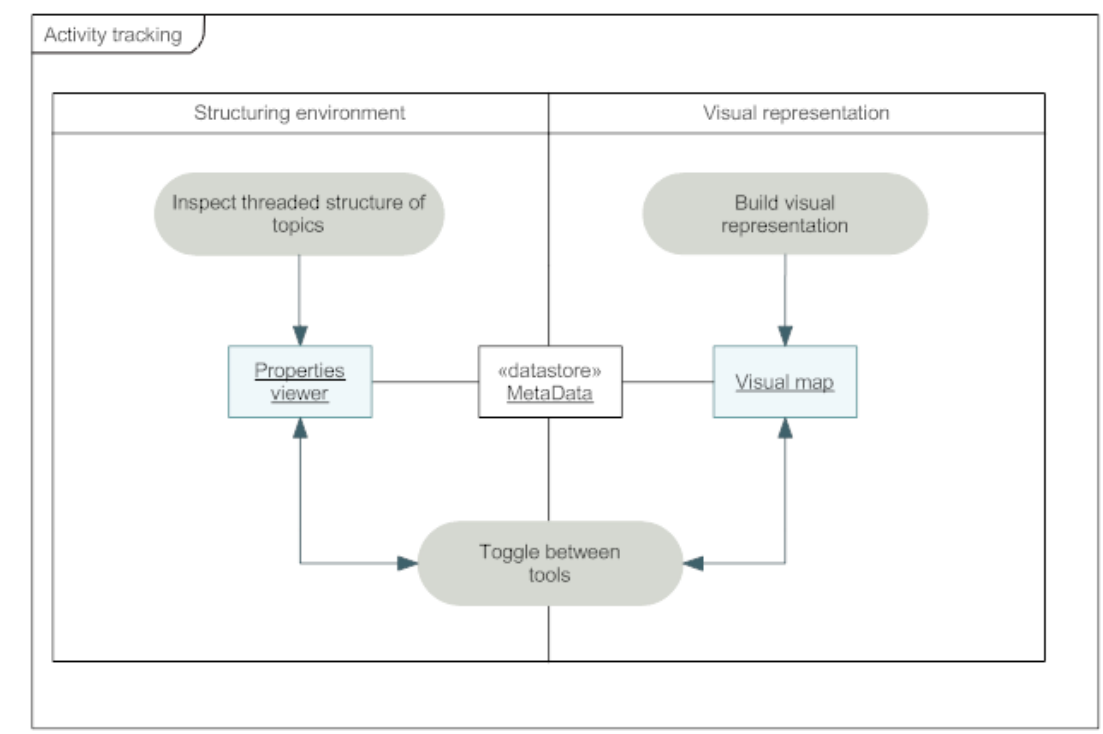

Figure 5: Activity tracking (activity diagram)

Although Fig. 6 only shows version linking of discussion topics, the $I C_{n}-M_{D}$ allows filtering and exhibiting the information elements in different ways (though actual implementation of the visual map only allows additional representation according to temporal sequence and argumentation structure). Fig. 6 also shows a snapshot of a visual layout being modified using the "design/edit map" tools. 


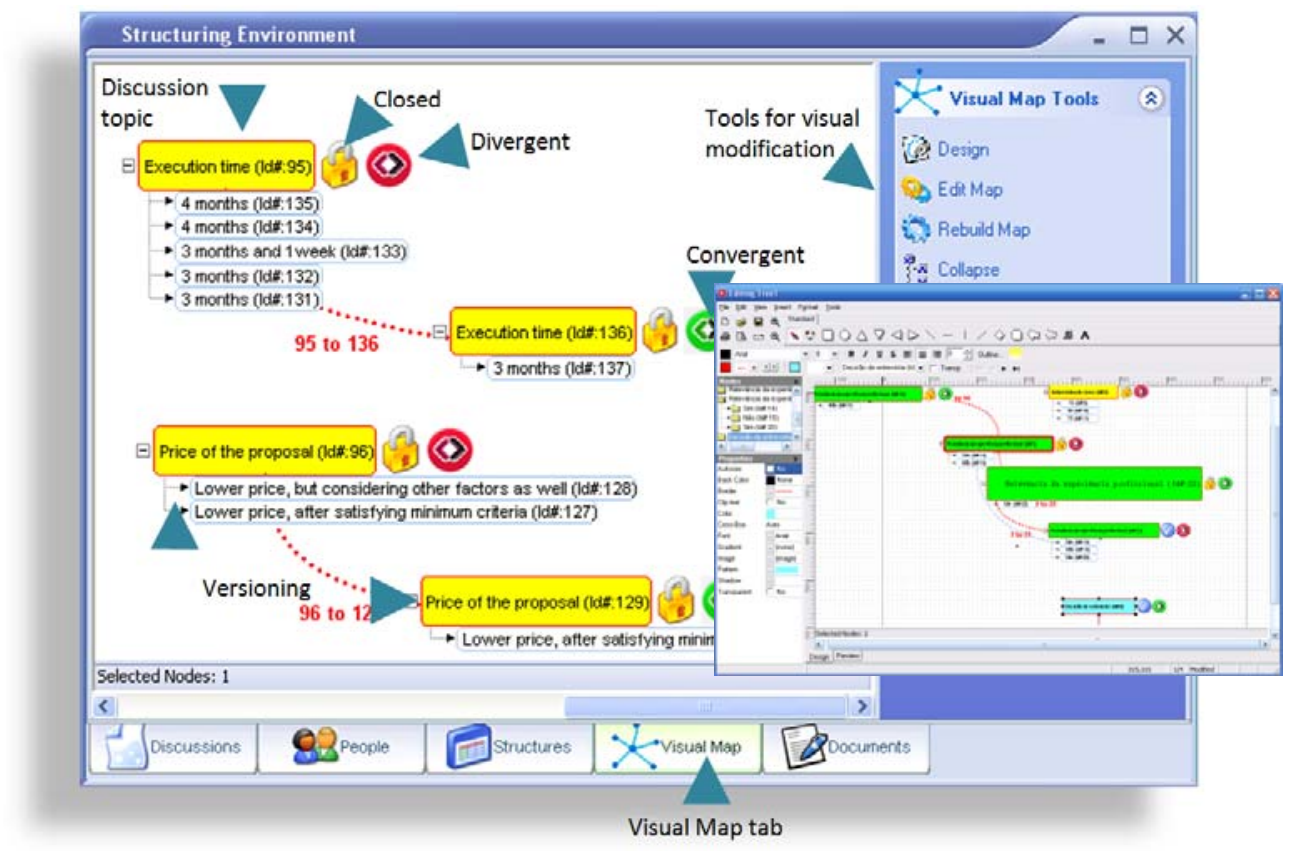

Figure 6: A snapshot of the visual map tool

\subsection{Structured documents}

The system also produces structured documents from the defined information structures, in order to create a more "traditional" document, as usually required in a business context. Documents refer to the discussions, topics, and contributions, without the need for any specialized computer skill. The only requirement is to drag the references onto the elements, from the structuring environment into the document, creating automatic links. Then, users can change the text of the automated links to compose the document, if they need to. When a user activates a link, the system traces back the information element and selects it from the structuring environment. This procedure allows the user to reconstitute the context and the reasons that led to its creation. The editing tool has two different views: the declaration view and the normal view. The former view permits working with the information structures and editing the document, while the later shows the documents as in an ordinary word processor.

As the structured documents are $I C_{n} s-M_{D}$, versioning is also feasible, making it possible to follow documents from their start to their most recent versions, as shown in Figures 7 and 8. 


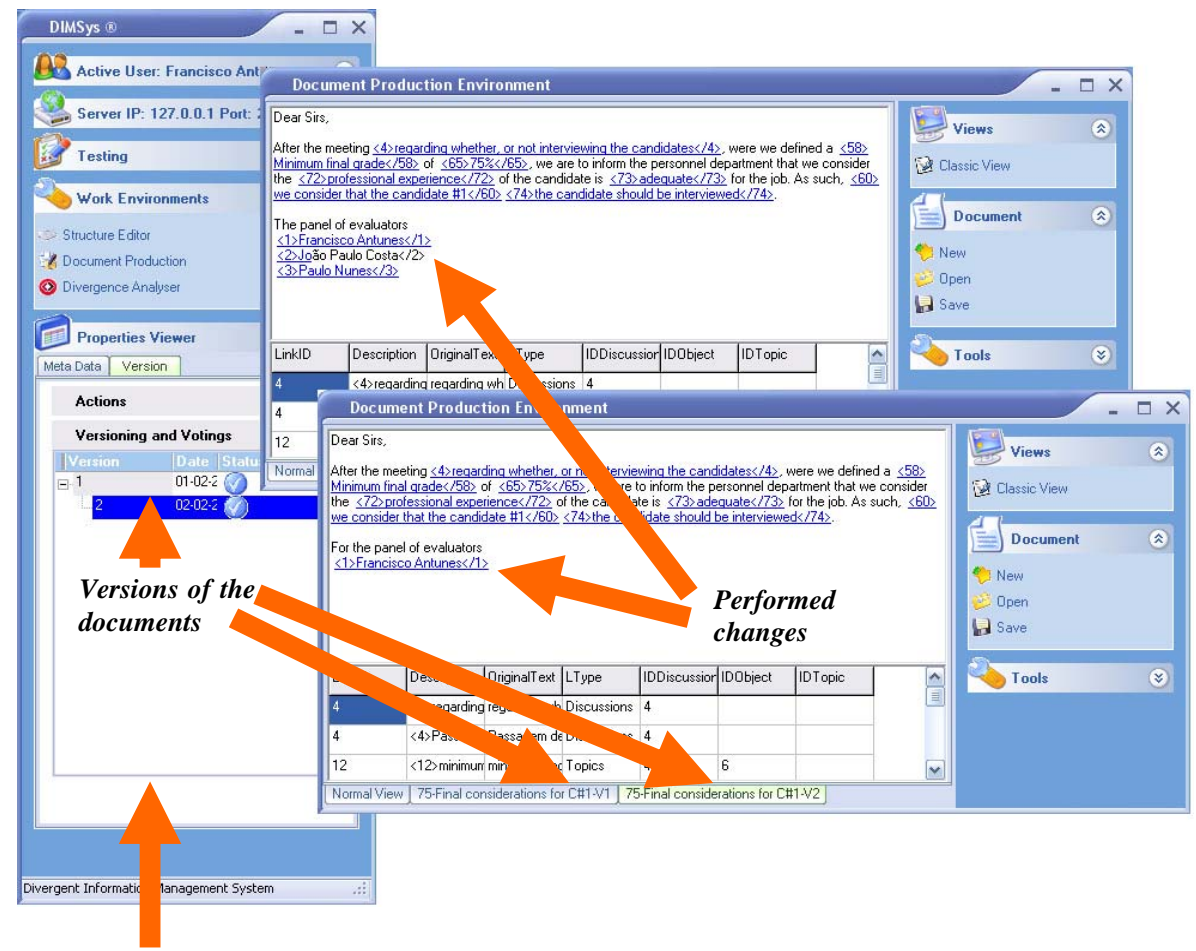

Properties viewer

Figure 7: The document production environment and versions of a document.

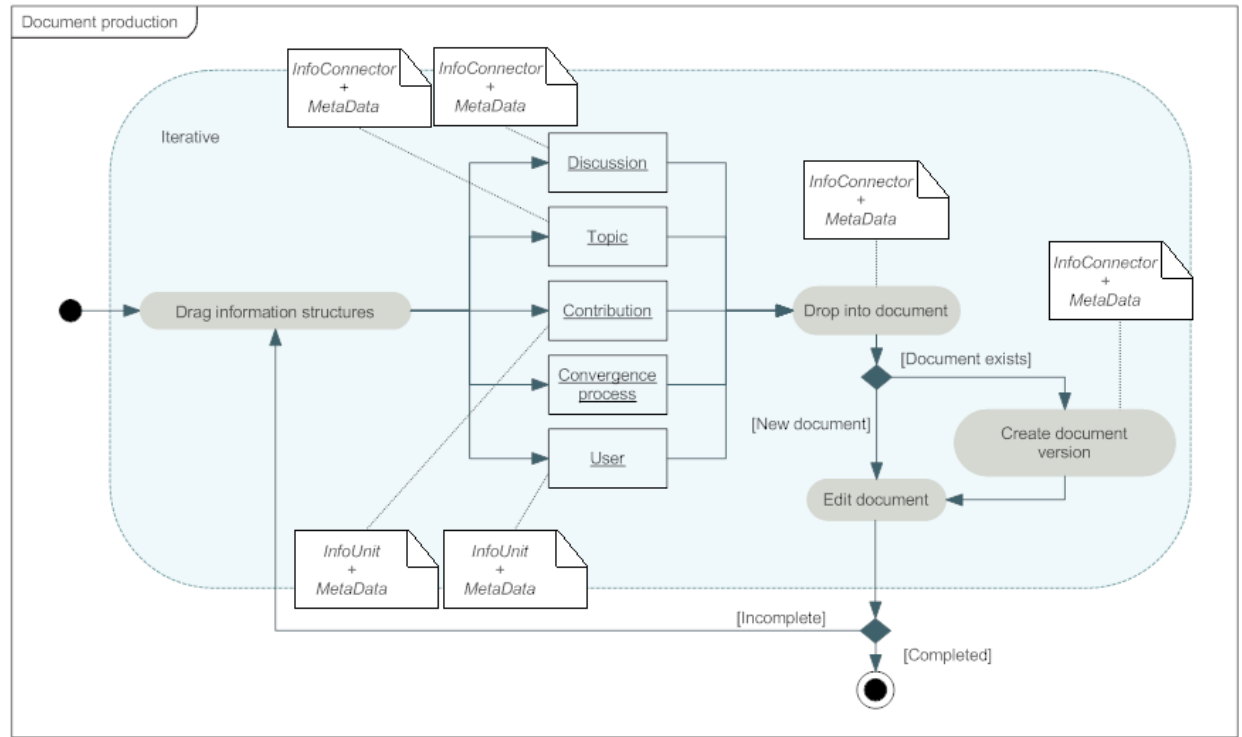

Figure 8: Document production (activity diagram) 


\section{Case study}

It is commonly assumed that an experienced GSS user is familiar with the general tools and the activity sequence of a GSS-based decision process (such as idea generation, topic categorization, decision analysis, reporting, etc.). However, literature is quite scarce in describing such user's behavior when retrieving decisions by means of the aforementioned tools, especially when such decisions had no intervention from the referred users. One of the aims of this study was to deepen our research in order to assess if the proposed model would support the information needs of decision reviewers, as we had theorized (tool/model analysis objective). We were also interested in observing the behavior of decision reviewers when performing decision reconstruction (behavioral analysis objective).

\subsection{Methodology and settings}

Methodologically, our research lies within the scope of design research. This option takes into consideration the creation, use, study and performance evaluation of artifacts in order to understand, explain and improve information systems. ${ }^{49-50}$ There are many descriptions and diagrams of design research in information systems (e.g. Refs. 49-53), but we have adopted the process defined in Ref. 54. This was both because it is an eclectic approach, which combines the research steps of other authors, ${ }^{49,55-60}$ and because it emphasizes knowledge use and development, throughout the research.

The first iteration of the study demonstrated the feasibility of the proposed solution, ${ }^{58}$,

${ }^{61}$, by applying a GSS to the information model for decision reconstruction, as described in section 4. The second round required explanatory work or observational testing (as regarded in Refs. 49-50, 62), for which we defined two units of analysis: structuring capability and storytelling capability. These units allowed us to measure, respectively, the ability to structure a group's discussion and the second allows measuring and the ability to retrieve information from previous discussions. Table 2 and Table 3 present the division of these units into metrics, as well as their descriptions.

With this study, we intended to emulate the extreme case in which recalling the reasons for a past resolution is solely dependent of previous GSS records, seeing that no reviewer was involved in the decision. The scenario was built upon the need to assess the correctness of a contracting process, performed in a public company, regarding the acquisition of external auditing services, according to existing legislation requirements. As our main concern was to observe the reconstruction process, we codified the past decision process, using our GSS (briefly described ahead). We divided the discussion into different discussion topics, which ranged from the financial elements submitted by each applicant and their proposals for the price and time limit for executing the task, to the contributions of applicants and decision agents.

The idea-generation phase relied on a simple reply-response scheme, while the debate and consensus building required a more structured representation, which implied evidencing the arguments (support/rebuttal) as well as the sequence (versions or steps) of the convergence processes, expressed through textual discussion and online voting. A 
final document, which represented the formal outcome of the decision process, was also included.

Table 2: Structuring capability

\begin{tabular}{ll}
\hline Metrics & Description \\
\hline $\begin{array}{l}\text { 1. Contribution } \\
\text { posting }\end{array}$ & $\begin{array}{l}\text { This measure intends to register the ability of the developed GSS } \\
\text { to structure a group's discourse, using the defined argumentation } \\
\text { elements, namely through contribution posting. }\end{array}$ \\
\hline $\begin{array}{l}\text { 2. Relationship } \\
\text { management }\end{array}$ & $\begin{array}{l}\text { This measure intends to register the ability of the developed GSS } \\
\text { to manage (perform changes and register alterations) the } \\
\text { established relationships among the argumentation elements. }\end{array}$ \\
\hline $\begin{array}{l}\text { 3. Structure } \\
\text { awareness }\end{array}$ & $\begin{array}{l}\text { This measure intends to register the ability of the developed GSS } \\
\text { to evidence the structure of a group's discourse, as well as to } \\
\text { inform the users of performed changes (an in-depth study about } \\
\text { the importance of awareness in GDSS can be found in Ref. 63). }\end{array}$ \\
\hline $\begin{array}{l}\text { 4. Idea } \\
\text { transmission }\end{array}$ & $\begin{array}{l}\text { This measure intends to register the adequateness of the developed } \\
\text { GSS to elaborate on complex ideas using the defined } \\
\text { argumentation elements and posting procedures. }\end{array}$ \\
\hline $\begin{array}{l}\text { 5. Documental } \\
\text { elaboration }\end{array}$ & $\begin{array}{l}\text { This measure intends to register the ability of the developed GSS } \\
\text { to produce structured documents based on the argumentation } \\
\text { elements. }\end{array}$ \\
\hline
\end{tabular}

Table 3: Storytelling capability

\begin{tabular}{lll}
\hline Metrics & Description \\
\cline { 2 - 3 } $\begin{array}{l}\text { 1. Structure } \\
\text { storytelling }\end{array}$ & $\begin{array}{l}\text { This metric intends to register the ability of the developed GSS to } \\
\text { retrieve a discourse from the structural representation of the used } \\
\text { argumentation elements, within a discussion. }\end{array}$ \\
\cline { 2 - 3 } & $\begin{array}{l}\text { 2. Documental } \\
\text { storytelling }\end{array}$ & $\begin{array}{l}\text { This metric intends to register the ability of the developed GSS to } \\
\text { retrieve a discourse from the visual representation of the used } \\
\text { argumentation elements within a discussion, using the visual map. }\end{array}$ \\
\hline $\begin{array}{l}\text { 3. Cognitive } \\
\text { load }\end{array}$ & $\begin{array}{l}\text { This metric intends to register the ability of the developed GSS to } \\
\text { retrieve a discourse combining the use of the structuring } \\
\text { environment of the developed GSS with the use of its visual map } \\
\text { tool. }\end{array}$ \\
\hline $\begin{array}{l}\text { 4. Haziness } \\
\text { avoidance }\end{array}$ & $\begin{array}{l}\text { This metric intends to register whether the developed GSS is able } \\
\text { to avoid vagueness attributable to issues that are not clearly } \\
\text { explained, using the argumentation elements and procedures. }\end{array}$ \\
\hline
\end{tabular}


As a control element, we introduced a biased voting process when discussing how significant the price factor should be to the analysis of the proposals. The situation meant that the group leader (the mediator) unilaterally attributed that weight, when the group was not able to solve its differences after several voting procedures. This had an impact on the chosen applicant. The introduction of this control mechanism would allow us to observe whether the discussion elements granted the subject group the information needed to perceive that the final decision could have been different.

Details pertaining of the formal structure of the discussion (like the organization, sequence of topics, reporting procedures, etc.) and the existence of any implied argumentation model were deliberately omitted.

Having codified the earlier elements, we invited seven senior technicians - the subject group - to review the decision process using our GSS. The reviews were made in independent sessions (meaning that the reviewers had no contact among them), in which we observed their behavior when performing the proposed tasks. Although being experienced with both management and group support systems usage, the subject group had no practice in using our GSS, and only had a basic written tutorial on how to operate the system.

After examining the decision process, we presented the metrics of the defined units of analysis and asked the subject group to rate them. To assess the accuracy of the decision reconstruction, we also asked them to write down a detailed report of the situation, taking into consideration the need to address a discussion outline (summary), the storytelling sequence and authoring, the existence of divergent topics, applied convergence techniques and achieved result(s).

\subsection{Results and discussion}

All the members of the subject group understood and correctly described the decision process. Although we did not consider the time to complete the task, we found that each member took about 45 minutes to learn how to use the tool and to grasp the key elements of the decision process.

Although knowing that the scores of the metrics for the defined units of analysis are not statistically relevant, the obtained results were around the middle of the used scale (fair/good), as shown in the appendix.

Probably the most important insights from the study were drawn from observing the reviewers. When writing down the proposed reports, all of them went back to using the prototype. The fast and recurring reuses of the tool were not accounted, but they seem to explain the accuracy level of the descriptions. We found that the decision process was reconstructed using one of four different processes, namely:

- by starting with the use of the document production tools to analyze the produced document and then jumping into the structuring environment for details;

- by starting with the use of the visual map tool, to visually analyze the structure, and then making occasional jumps into the structuring environment; 
- by starting with the use of the structuring environment, in order to retrieve details from the discussion, and then jumping to the visual map tool, in order to acquire "big pictures" of the relationships among the elements;

- and by performing a hybrid approach using a combination of the previous processes (e.g. by starting with the use of the document production tools, for some part of the reconstruction process, and starting by using another working environment for other parts).

As the produced document integrated links (InfoConnectors) to the contributions represented in the structuring environment (InfoUnits), it allowed the subject group to switch between the discussion environment and the document production environment. This enabled the subject group to gather in-depth details of the elements that were captured from and expressed in the document.

The switching feature was described as useful and suited to the reconstruction process, but we found that it might not guarantee per se the accuracy of the reconstruction.

As the mediator was responsible for producing the final document, the process of selecting and dragging the key issues of the decision into the "traditional" document (the decision report) relied solely on the mediator's personal judgment. When reviewing the final report, some members of the subject group stated that a number of reported reasons for the final decision were irrelevant, while others agreed that those reasons helped them to understand the decision outcome. This situation means that a decision reviewer might not share the relevance pattern or judgment assessment of the reasons expressed in the produced documentation, hindering decision reconstruction. In this case, a collaborative construction of the document could have mitigated the problem, as it would integrate different perspectives into the final report. Nevertheless, and though outside the scope of the information model itself, it would be interesting if the GSS could parameterize automatic recording procedures (coarse or fine grained), which would be, therefore, userindependent, in order to produce a final document or report.

All members of the subject group, but one, found that representing the relationships between the discussion elements on a visual map improved the perception of the discussion as a whole and constituted a friendly environment for getting "big pictures" of the discussion or topics. However, they also noted that the simultaneous representation of all the associations between discussion elements made the information hard to follow. Therefore, the capture of the relationships between the discussion elements covered by the information model provides the necessary basis for its visual representation. In order to enhance its utility in decision reconstruction and especially to respond to different information needs and cognitive styles of decision reviewers, it requires, nevertheless, a combination with tools for filtering, sorting, selecting and displaying multiple relationships.

Another common aspect of the reports was that the members of the subject group experienced a great deal of effort in understanding that different representation schemes (argumentation models) were involved in the decision process, as they expected an athwart representation for the whole discussion. The modeling possibilities of the prototype were found to be excellent in supporting several ways of conducting a decision 
process, as they made possible the use of different types of argumentation models and representation styles within a decision process. However, such freedom of style was also pointed out to be a problem for the decision reconstruction.

These findings ratified our earlier expectations, since we had anticipated that using the GSS without any knowledge on how the discussion was organized or on the used argumentation schemes in the different phases of the decision process would increase the difficulty of the reconstruction. This situation seemed, however, more adequate to our goals in testing the model/system and more realistic in emulating the situation in which the decision reviewer was not part of the decision group. Nevertheless, it would be interesting to assess the difference of results if the argumentation models and structure details of the discussion were given beforehand.

As the process of capturing the discussion elements and their relationships follows predefined argumentation models, a corollary of the above observation is that the selection of basic argumentation models might imply that only a restricted number of relationships can be represented (e.g. the basic sequential process of a simple questionreply thread pattern). This situation might obstruct the decision reconstruction process. Thus, choosing an argumentation model should not be taken lightly.

\subsection{Limitations}

The reviewers commentaries showed that the used argumentation model (or models), as well as its rules and properties, should be explicitly evidenced, as it would decrease the cognitive load of decision reconstruction.

Observing the reviewers revealed different cognitive behaviors or at least different preferences when analyzing past information. All the members complained about the lack of re-structuring tools for the decision process information (argumentation elements and other data) that would let them analyze the past situation in their own way. To overcome this problem, some of the reports suggested the development of re-structuring tools.

To re-structure the expressed and visually represented information, using a certain argumentation model into another argumentation model and representation scheme, needs further thought. Expressing more complex argumentation models as simpler ones, for instance from Toulmin's argumentation model, ${ }^{35}$ into a question-reply model, does not seem troublesome. The opposite, however, may not be accomplishable (at least automatically) due to the lack of associated information. Producing such information, within the presented model, would require the establishment of new types of associations (through InfoConnectors/Meta-data) beyond the ones established in the decision process.

We believe that two processes (or their combination) could be tried, in order to achieve the desired situation. The first one would be the reviewer's manual supply of the relationship properties as individually perceived. To support this process, the GSS should ask the reviewer to input all the necessary association attributes, according to the intended argumentation model. The second procedure could use automatic mechanisms, i.e. intelligent agents or semantic technologies, to perform a semantic and syntactic analysis of the different contributions and propose the type of detected relationships (again, according to a selected argumentation model) to be confirmed by the decision 
reviewer. In order to reduce information ambiguity across discussion the development of an ontology builder, from personal annotations within Meta-data, using the concept of "folksonomies", ${ }^{64-65}$ could also be tried, along with ETL (Extraction, Transformation and Load) procedures to facilitate data movement and transformation.

Another problem regards the visual representation of information components. In the presented case-study no problems were found when using the visual map tool. However, in previous testing we found that a large amount of information elements (the most intensive test involved fifty thousand computer-generated components - a theoretical number if we consider a real life situation) compromised the normal use of the visual map toolkit. Nevertheless, the inspection of the information components revealed no inconsistencies. This demonstrated that the decision reconstruction model scales well in large scenarios, though requiring a more robust toolkit for visual representation.

In spite of the fact that important insights have been gained, there are questions that are still left unsolved. Knowing whether found results will apply in different decision settings still requires further investigation. Being a more or less structured decision task, having a larger number of decision reviewers, baring different convergence processes, having decisions with intertwined discussions in distinct moments in time, different backgrounds in using GSS. What would happen if some information elements were deleted (for instance, due to a court order)? What is the threshold for deleting information, but still preserving the ability to reconstruct a decision? Which type of information is more likely to deteriorate the ability for decision reconstruction if deleted? Is there any threshold for determining the overall accuracy of the decision reconstruction? These are just a few questions and decision scenarios that need to be dealt with.

\section{Final remarks and future research}

In this paper, we have presented an information model to support decision reconstruction. We tested this model through a public contracting process supported by our GSS. A group of people later reviewed the abovementioned process, in order to reconstruct the decision. Their reports demonstrated that the subject group was able to use the GSS prototype to accurately rebuild the decision process under analysis. When conducting the reconstruction process, which was reported to require a great deal of effort as no details on the used argumentation schemes were provided, the reviewers implemented different processes.

The presented model proved adequate in dealing with the decision reconstruction, but the Meta-data element still needs, in order to lower the cognitive effort of decision reviewers, expanded properties to support a more flexible process. Evidencing the used argumentation and representation schemes to the reviewers in the reconstruction process, and building re-structuring tools based on the transition between such argumentation models was also found very important.

Some attempts to define the basic set of meta-data to be associated with information elements have already been made (e.g. PRISM, Dublin Core, Resource Description Framework - RDF, DARPA Agent Markup Language + Ontology Inference Layer 
(DAML+OIL), XML Topic Maps - XTM, Web Ontology Language, etc.), though a normalized framework is still far from being achieved. Nevertheless, it seems important to incorporate those ideas in the Meta-data element in order to build a dynamic base that allows the transition between different ways of representing group discussions, especially regarding the presentation of a discussion discourse and its visual representation, thereby reinforcing its multidimensional scope.

\section{Acknowledgements}

We thank the subject group for all the time and effort dedicated to the case study. In addition, we would like to thank the anonymous reviewers for their constructive commentaries that greatly improved the focus of this paper. This work has been partially supported by FCT under project grant PEst-C/EEI/UI0308/2011. 


\section{Appendix A. Evaluation metrics and scores}

\begin{tabular}{|c|c|c|c|c|c|c|c|}
\hline & \multicolumn{7}{|c|}{ Subject group } \\
\hline & Tech.1 & Tech.2 & Tech. 3 & Tech. 4 & Tech.5 & Tech.6 & Tech.7 \\
\hline \multicolumn{8}{|l|}{ Metrics } \\
\hline $\begin{array}{l}\text { 1. Contribution } \\
\text { posting }\end{array}$ & Fair & Good & Fair & Good & Good & Good & Good \\
\hline $\begin{array}{l}\text { 2. Relationship } \\
\text { management }\end{array}$ & Fair & Good & Poor & Good & Good & Good & Good \\
\hline $\begin{array}{l}\text { 3. Structure } \\
\text { awareness }\end{array}$ & Good & $\begin{array}{l}\text { Very } \\
\text { good }\end{array}$ & Fair & Fair & Fair & Fair & Good \\
\hline $\begin{array}{l}\text { 4. Idea } \\
\text { transmission }\end{array}$ & Fair & Good & Fair & Fair & Good & Good & Good \\
\hline $\begin{array}{l}\text { 5. Documental } \\
\text { elaboration }\end{array}$ & $\begin{array}{l}\text { Very } \\
\text { good }\end{array}$ & Good & Good & $\begin{array}{l}\text { Very } \\
\text { good }\end{array}$ & $\begin{array}{l}\text { Very } \\
\text { good }\end{array}$ & Good & $\begin{array}{l}\text { Very } \\
\text { good }\end{array}$ \\
\hline \multicolumn{8}{|l|}{ Metrics } \\
\hline $\begin{array}{l}\text { 1. Structure } \\
\text { storytelling }\end{array}$ & Good & Good & Fair & Good & Fair & Good & Good \\
\hline $\begin{array}{l}\text { 2. Documental } \\
\text { storytelling }\end{array}$ & Poor & $\begin{array}{l}\text { Very } \\
\text { good }\end{array}$ & $\begin{array}{l}\text { Very } \\
\text { poor }\end{array}$ & $\begin{array}{l}\text { Very } \\
\text { good }\end{array}$ & Good & Good & Good \\
\hline $\begin{array}{l}\text { 3. Cognitive } \\
\text { load }\end{array}$ & Fair & Fair & Fair & $\begin{array}{l}\text { Very } \\
\text { good }\end{array}$ & Good & Good & Good \\
\hline $\begin{array}{l}\text { 4. Haziness } \\
\text { avoidance }\end{array}$ & Fair & Good & Fair & $\begin{array}{l}\text { Very } \\
\text { good }\end{array}$ & Good & Good & Good \\
\hline
\end{tabular}

\section{References}

1. D. J. Power, R. Sharda and U. R. Kulkarni, in Decision Support for Global Enterprises, (Springer US, 2007, vol. 2), pp. 3-14.

2. C. Kim, Y.-J. Son, T. Kim and K. Kim, A virtual enterprise design method based on business process simulation, International Journal of Computer Integrated Manufacturing, 21(2008), 857-868.

3. T. J. Strader, F.-R. Lin and M. J. Shaw, Information infrastructure for electronic virtual organization management Decision Support Systems, 23(1998), 75-94.

4. N. Venkatraman and J. C. Henderson, Real Strategies for Virtual Organizing, Sloan Management Review, Fall 1998(1998), 33-48.

5. Y. I. Liou and J. F. Nunamaker, Using a Group Decision Support System Environment for Knowledge Acquisition: A Field Study, Proc. Proceedings of the Twenty-Third Annual Hawaii International Conference, 1990), pp. 40-49.

6. E. W. Stein and V. Zwass, Actualizing organizational memory with information systems, Information Systems Research, 6(1995), 85-117.

7. J. F. Nunamaker, A. R. Dennis, J. S. Valacich, D. R. Vogel and J. F. George, Electronic Meetings Systems to Support Group Work, Communications of the ACM, 34(1991), 40-61.

8. G.-J. Vreede, D. Vogel, G. Kolfschoten and J. Wien, Fifteen years of GSS in the field: a comparison across time and national boundaries, Proc. 36th Hawaii International Conference on System Sciences (CD-ROM), 2003).

9. R. Kwok, J. Ma and D. Vogel, Effect of GSS and Facilitation on Knowledge Restructuring, Proc. 33rd Hawaii International Conference on System Sciences (CD-ROM), (Hawaii, 2000). 
10. J. Osborne, Arguing to Learn in Science: The Role of Collaborative, Critical Discourse, Science, 328(2010), 463-466.

11. S. Paul, W. D. Haseman and K. Ramamurthy, Collective memory support and cognitiveconflict group decision-making: an experimental investigation, Decision Support Systems, 36(2004), 261-281.

12. G. Bafoutsou and G. Mentzas, Review and functional classification of collaborative systems, International Journal of Information Management, 22(2002), 281-305.

13. R. K. Maier, Knowledge Management Systems: Information and Communication Technologies for Knowledge Management, (2nd Edition edn., Springer-Verlag, Berlin, 2004).

14. J. Gunnlaugsdottir, Seek and you will find, share and you will benefit: organising knowledge using groupware systems, International Journal of Information Management, 23(2003), 363380 .

15. D. Arnott and G. Pervan, A critical analysis of decision support systems research, Journal of Information Technology, 20(2005), 67-87.

16. H. Simon, The New Science of Management Decision, Prentice Hall, Englewoods Cliffs, NJ, 1977).

17. M. Turoff, M. Chumer, S. R. Hiltz, R. Klashner, M. Alles, M. Vasarherlyi and A. Kogan, Assuring Homeland Security: Continuous Monitoring, Control, and Assurance of Emergency Preparedness, Journal of Information Technology Theory and Application (JITTA), 6(2004), 124.

18. M. Turoff, M. Chumer, B. Van de Walle and X. Yao, The design of a dynamic emergency response management information system (DERMIS), Journal of Information Technology Theory and Application (JITTA), 5(2004), 1-35.

19. M. Turoff, S. R. Hiltz, M. Bieber, J. Fjermstad and A. Rana, Collaborative Discourse Structures in Computer Mediated Group Communications, Proc. 32nd Hawaii International Conference on System Sciences (CD-ROM), (Hawaii, 1999).

20. M. Danielson, L. Ekenberg, Ä. Grönlund and A. Larsson, Public Decision Support - Using a DSS to Increase Democratic Transparency, International Journal of Public Information Systems, 1(2005), 3-25.

21. L. Stirton and M. Lodge, Transparency Mechanisms: Building Publicness into Public Services, Journal of Law and Society, 28(2001), 471-489.

22. Commission of the European Communities, Green paper: European Transparency Initiative, 2006.

23. M. Turoff, Future Opportunities for Group Decision and Negotiations, Proc. Group Decision and Negotiation (GDN) 2006, (Karlsruhe, Germany, 2006), pp. 12-14.

24. J. A. Hoffer and J. S. Valacich, in Group support systems: new perspectives, eds. L. M. Jessup and J. S. Valacich, (Macmillan Publishing Company, 1993), pp. 214-229.

25. J. P. Walsh and G. R. Ungson, Organizational Memory, The Academy of Management Review, 16(1991), 57-91.

26. F. Lehner and R. K. Maier, How Can Organizational Memory Theories Contribute to Organizational Memory Systems?, Information Systems Frontiers, 2(2000), 277-298.

27. M. S. Ackerman, Augmenting Organizational Memory: A Field Study of Answer Garden, ACM Transactions on Information Systems, 16(1998), 203-224.

28. D. L. McClain and R. J. Aldag, Complexity and familiarity with computer assistance when making ill-structured business decisions, International Journal of Information Technology \& Decision Making, 8(2009), 407-426.

29. M. Turoff, S. R. Hiltz, M. Bieber, J. Fjermstad and A. Rana, Collaborative Discourse Structures in Computer Mediated Group Communications, Journal of Computer-Mediated Communication, 4(1999), 1050-1079.

30. S.-Y. Hung, K.-Z. Tang and T.-C. Shu, Expanding Group Support System Capabilities from the Knowledge Management Perspective, Journal of International Technology and Information Management, 17(2008), 21-42. 
31. T. J. Siddiqui and U. S. Tiwary, Utilizing Local Context for Effective Information Retrieval, International Journal of Information Technology \& Decision Making, 7(2008), 5-21.

32. E. Atlam, A new approach for text similarity using articles, International Journal of Information Technology \& Decision Making, 7(2008), 23-34.

33. L. A. Guerrero and J. A. Pino, Understanding organizational memory, Proc. XXI International Conference of the Chilean Computer Science Society, (Punta Arenas, Chile, 2001), pp. 124132.

34. W. Kunz and H. Rittel, Studiengruppe für Systemforschung, Heidelberg, Germany, Editon edn., 1979.

35. S. Toulmin, The Uses of Argument - Updated Edition, Cambridge University Press, Cambridge, 2003).

36. K. Maleewong, C. Anutariya and V. Wuwongse, A Collective Intelligence Approach to Collaborative Knowledge Creation, Proc. Fourth International Conference on Semantics, Knowledge and Grid (SKG), (Beijing: China, 2008), pp. 64-70.

37. J. Bentahar, B. Moulin and M. Bélanger, A Taxonomy of Argumentation Models used for Knowledge Representation, Artificial Intelligence Review, 33(2010), 211-259.

38. R. Robbes and M. Lanza, Versioning Systems for Evolution Research, Proc. Eighth International Workshop on Principles of Software Evolution (IWPSE'05), 2005), pp. 1-10.

39. G. E. Kersten and H. Lai, Negotiation Support and E-negotiation Systems: An Overview, Group Decision and Negotiation, 16(2007), 553-586.

40. R. O. Briggs, G.-J. d. Vreede, J. F. Nunamaker and D. Tobey, ThinkLets: Achieving Predictable, Repeatable Patterns of Group Interaction with Group Support Systems (GSS), Proc. 34th Hawaii International Conference on System Sciences (CD/ROM), (Hawaii, 2001).

41. J. H. Helquist, J. Kruse and M. Adkins, Participant-Driven Collaborative Convergence, Proc. 41st Hawaii International Conference on System Sciences (CD-ROM), (Hawaii, 2008).

42. I. Lopatovska and H. B. Mokros, Willingness to pay and experienced utility as measures of affective value of information objects: User's accounts, Information Processing \& Management, 44(2008), 92-104.

43. C. Y. Lee, A knowledge management scheme for meta-data: an information structure graph, Decision Support Systems, 36(2004), 341-354.

44. J. Zhang and T. Nguyen, WebStar: a visualization model for hyperlink structures, Information Processing \& Management, 41(2005), 1003-1018.

45. F. Crestani, J. Vegas and P. Fuente, A graphical user interface for the retrieval of hierarchically structured documents, Information Processing \& Management, 40(2004), 269289.

46. C. Standing and S. Benson, Irradiating intranet knowledge: the role of the interface, Journal of Knowledge Management, 4(2000), 244.

47. S. Smolnik and I. Erdmann, Visual navigation of distributed knowledge structures in groupware-based organizational memories, Business Process Management Journal, 9(2003), 261-280.

48. M. Misek, TheBrain Technologies Corporation: Collapsing the Time to Knowledge, EContent, 26(2003), 44.

49. A. R. Hevner, S. T. March, J. Park and S. Ram, Design Science in Information Systems Research, MIS Quarterly, 28(2004), 75-105.

50. S. T. March and G. F. Smith, Design and natural science research on information technology, Decision Support Systems, 15(1995), 251-266.

51. R. Cole, S. Purao, M. Rossi and M. K. Sein, Being Proactive: Where Action Research Meets Design Research, Proc. International Conference on Information Systems, ICIS 2005, (Las Vegas, NV, USA, 2005), pp. 1-21.

52. D. G. Gregg, U. R. Kulkarni and A. S. Vinzé, Understanding the Philosophical Underpinnings of Software Engineering Research in Information Systems, Information Systems Frontiers, 3(2001), 169-183. 
53. V. Vaishnavi and W. Kuechler, Design Research in Information Systems, (2004/5), http://www.isworld.org/Researchdesign/drisISworld.htm

54. K. Peffers, T. Tuunanen, C. E. Gengler, M. Rossi, W. Hui, V. Virtanen and J. Bragge, The Design Science Research Process: A Model for Producing and Presenting Information Systems Research, Proc. First International Conference on Design Science Research in Information Systems and Technology, (Claremont, CA, 2006), pp. 83-106.

55. H. Takeda, P. Veerkamp, T. Tomiyama and H. Yoshikawa, in AI Magazine, Editon edn., 1990, vol. Winter, pp. 37-38.

56. J. Eekels, On the fundamentals of engineering design science: The geography of engineering design science. Part 1, Journal of Engineering Design, 11(2000), 377-397.

57. J. Eekels, On the fundamentals of engineering design science: The geography of engineering design science. Part 2, Journal of Engineering Design, 12(2001), 255-281.

58. J. F. Nunamaker and M. Chen, Systems Development in Information Systems Research, Proc. 23rd Hawaii International Conference on System Sciences, (Hawaii, 1990), pp. 631-640.

59. J. G. Walls, G. R. Widmeyer and O. A. El Sawy, Building an Information System Design Theory for Vigilant EIS, Information Systems Research, 3(1992), 36-59.

60. M. Rossi and M. K. Sein, Design Research workshop:A proactive research approach, Proc. Design Research Workshop IRIS26, (Haikko Manor, Porvoo, Finland, 2003), pp. 1-20.

61. V. K. Vaishnavi and W. Kuechler Jr., Design science research methods and patterns : innovating information and communication technology, Auerbach Publications, Boca Raton, 2008).

62. R. Yin, Case Study Research, Sage Publications, Inc., London, 2003).

63. N. Jongsawat and W. Premchaiswadi, A study of two different experimental settings for group awareness information In a web-based group decision support system, International Journal of Information Technology \& Decision Making, 10(2011), 231-268.

64. A. Hotho, R. Jäschke, C. Schmitz and G. Stumme, in ESWC 2006, LNCS 4011, eds. Y. Sure and J. Domingue, (Springer-Verlag Berlin Heidelberg, 2006), pp. 411-426.

65. L. Specia and E. Motta, in ESWC 2007, LNCS 4519, eds. E. Franconi, M. Kifer and W. May, (Springer-Verlag Berlin Heidelberg, 2007), pp. 624-639. 